\title{
English Language Learning Strategy Use by Chinese Senior High School Students
}

\author{
Yaping Zhou \\ Foreign Languages School, Zhejiang Ocean University \\ 18 Haiyuan Road, Dinghai District, Zhoushan City, Zhejiang Province, 316000, China \\ Tel: 86-580-818-0286 E-mail: zyp@zjou.edu.cn
}

\begin{abstract}
Language learning strategies are important factors that affect students' learning. In China, senior high school is an important stage in a person's education. This study examines the English language learning strategy use by Chinese senior high school students by means of the Strategy Inventory for Language Learning. The findings reveal that Chinese senior high school students use compensation strategies most frequently; that significant differences exist between male students and female students with female students using strategies more frequently than males; and that differences also exist in the strategy use among the three grades. The reasons for these differences in strategy use by Chinese senior high school students are discussed and implications for the future language learning strategy training and English teaching are put forward.
\end{abstract}

Keywords: English Language learning strategies, Senior high school students, Strategy training, English Teaching

\section{Introduction}

With the development of the research on second language acquisition, more and more attention has been paid to the research on individual learner differences. Among those, language learning strategies have been increasingly attracting the interest of contemporary educators as they have potential to enhance learning. Learning strategies are claimed to have the principal influence on the rate and level of second language acquisition (Ellis, 1994; Oxford, 1990). Over the years, many researchers have studied and examined the language learning strategies. However, the results of the studies are different and controversial. Most of the research subjects in these studies are students in different colleges and universities. There is little in the literature that focuses on the language learning strategies of students learning English in senior high schools. In China, senior high school is a very important stage in a person's life because the study in senior high school determines whether a person can go to have higher education or not and what kind of higher education a person can have. Therefore, the teaching in the Chinese senior high schools is quite different from that in universities or colleges and the students in senior high schools have their own peculiar ways of learning. In order to provide more evidence for the research of language learning strategies, this study aims to examine the language learning strategy use by senior high school students in China. The following research questions are addressed in this study.

1) What is the general pattern of language learning strategies by senior high school students in China?

2) What are the differences between male and female students in using language learning strategies?

3) Are there any differences in strategy use among students in different grades?

\section{Literature review}

\subsection{Definition and classification of language learning strategies}

Since the mid-seventies, more and more researchers and teachers in ESL field have realized the importance of the strategies used by learners in the language learning process. But as for the definition and classification of the language learning strategies, researchers have different opinions. Robin (1975:43) defined the learning strategies as 'the techniques or devices that a learner may use to acquire knowledge'. In her later research, she identified two kinds of learning strategies: those that contribute directly to learning, and those that contribute indirectly to learning. The direct learning strategies include clarification/verification, monitoring, memorization, guessing/inductive inferencing, deductive reasoning, and practice. The indirect learning strategies are creating opportunities for practice and production tricks. Stern, in 1975, also produced a list of ten language learning strategies which he believed to be characteristic of good language learners. Later, Stern (1992:261) defined 'strategies' as 'broadly conceived intentional directions'. O'Malley et al (1985:23) identified learning strategies as being 'operations or steps used by a learner that will facilitate the acquisition, storage, retrieval or use of information', which was originally used by Rigney (1978). They identified 26 strategies, which can be divided into three categories: metacognitive (knowing about learning), cognitive (specific to distinct learning activities) and social. Oxford (1990:8) also used Rigney's 
definition, described language learning strategies as 'operations employed by the learner to aid the acquisition, storage, retrieval or use of information'. However, she classified learning strategies into six groups: memory strategies, cognitive strategies, compensation strategies, metacognitive strategies, affective strategies and social strategies. These six groups in the later studies were further divided into direct strategies and indirect strategies. From the above, we can see that there is no consensus on the definition and classification of language learning strategies in the field of language learning strategy research.

\subsection{Research into language learning strategies}

Early learning strategy research was mostly about listing and classifying language learners' strategy use, esp. strategies used by good language learners (Robin, 1975; Stern, 1975). Later on, researchers attempted to investigate the relationship between language learning strategies and success in language development, strategy use and language proficiency. Green and Oxford (1995) found that language learning strategies of all kinds were used more frequently by higher level students. Griffiths (2003) also discovered a positive correlation between course level and reported frequency of language learning strategy use. Park (1997) revealed a positive linear relationship between strategy use and language proficiency.

Many studies have also been done to investigate the factors affecting strategy choice or strategy use. A great deal of evidence has been found on the gender differences in the use of language learning strategies. Ehrman and Oxford (1989), Oxford and Nyikos (1989) and Green and Oxford (1995) discovered distinct gender differences in strategy use. The results showed that females were more frequent users of strategies. But in Ehrman and Oxford's another study done in 1990, they failed to discover any evidence of differing language learning strategy use between the sexes. The result of the study done by $\mathrm{Li}(2002)$ also showed that there was no significant difference between the employment of learning strategies and the students' gender in foreign language learning.

Another branch of studies done in the language learning strategy field is about the effects of strategy training. Many researchers have worked to apply the findings from previous studies into the pedagogical practice and come to the conclusions that language learning strategies are teachable and that learners can benefit from training in learning strategies (Cook, 1991; Larsen-Freeman, 1991; Oxford, 1990)

From the above literature review, we can see researchers differ in defining and classifying language learning strategies and that many studies have been done on language learning strategies. Although the results are different and controversial, the hypothesis that good language learners' success may be due to the use of more effective language learning strategies and the assumption that language learning strategies may be taught and trained to improve the learners' learning are appealing and worth being studied further.

\section{The study}

\subsection{Participants}

The participants involved in this study were 150 students from three different grades in a senior high school in Zhejiang province in China. These students were chosen at random from each grade, with 51 from Grade One, 49 from Grade Two and 50 from Grade Three. Of 150 students, 76 were male and 74 were female. All the participants were studying English as a foreign language and had studied English formally for three years in junior high schools and one or two more years in senior high schools. They had formed a set of stable learning methods. Permission to participating in the study was obtained from their teachers and participants were told to do the questionnaires carefully and objectively.

\subsection{Instruments}

In the study, the main data collection instrument was Oxford's Strategy Inventory for Language Learning (SILL) (Oxford 1990, Version 7.0), but some changes were made in order to suit this study. SILL is 'perhaps the most comprehensive classification of learning strategies' (Ellis, 1994) and 'has been widely employed by researchers all over the world' ( $\mathrm{Li}, 2002)$. SILL 'has been employed as a key instrument in numerous studies' (Hong-Nam and Leavell, 2006). Therefore, it was expected that the results of the current study could be compared with the previous studies. The questionnaire was made up of two sections. Section One was about participants' background information, such as name, class, sex, English proficiency, evaluation of English's importance, the reason for learning English, etc. Section Two consisted of 35 statements that were subdivided into 6 categories. They were Memory Strategies (A1----A8), Cognitive Strategies (B9----B16), Compensation Strategies (C17----C19), Metacognitive Strategies (D20----D26), Affective Strategies (E27----E29) and Social Strategies (F30----F35). Each statement was given a five-point scale (Likert Scale) ranging from "1" which refers to "I never use it", to "5" which means that "I always do it".

\subsection{Data collection and analysis}

The questionnaires were given to the participants by their teachers in English classes. The participants were 
informed of the purpose of the survey and of the fact that there was no right or wrong answer. They were also asked to express their honest opinions according to their own specific conditions by making the appropriate choice on the right side of each statement. The participants were able to complete the survey in about 20 minutes. Each completed questionnaire was manually examined, and all of 150 questionnaires were usable and used for statistical analysis.

The data from the SILL questionnaire sheets were analyzed with SPSS 10.0 to measure the learning strategy use. Descriptive statistics provided the means and standard deviations (SD) to analyze the participants' general pattern of language learning strategy use and the strategies frequently used and less frequently used. Independent sample tests were used to analyze the differences between male and female participants and among the three grades. Correlation analysis was conducted to examine the relationship between learning strategy use and gender.

\section{Results}

\subsection{The general pattern of language learning strategy use}

In order to assess the general pattern of language learning strategy use, the study calculated the mean and standard deviation of the six SILL categories respectively. As Oxford also divided learning strategies into two main groups: direct strategies (memory, cognitive and compensation strategies) and indirect strategies (metacognitive, affective and social strategies), we also calculated the descriptive statistics of the direct and indirect strategy groups. The details of the statistics were presented in Table 1.

In the study, generally speaking, students in senior high schools used direct strategies more than indirect strategies. According to Oxford's (1990) division of language learning strategy use (High usage is from 3.5 to 5.0; Medium usage is from 2.5 to 3.4; and Low usage is from 1.0 to 2.4), these participants used learning strategies at a medium level because the mean of the total was 2.77 . The means of each category, which ranged from 2.27 to 3.48 , also indicated that these students were medium users of language learning strategies. From Table 1, it could also be seen that, among the six categories, senior high school students used compensation strategies most frequently and social strategies least frequently. From this study, we can get the general pattern of language learning strategy use by these senior high school students in China, which is compensation, affective, metacognitive, cognitive, memory and social.

\subsection{The gender differences in language learning strategy use}

As shown in Table 2, the means of six categories ranged from a high one of 3.68 to a low one of 2.33 for females and from a high one of 3.29 to a low one of 2.22 for males. For male students, none of the 6 categories was in the high usage group, while for females there was 1 category which belonged to the high usage group. This table also indicated that both males and females used compensation strategies most frequently and social strategies least frequently. According to means of the total, it could be concluded that females used strategies more than males. This result was consistent with the findings of Green \& Oxford (1995), in which females used significantly more learning strategies than males.

Table 3 below showed the correlation between gender and learning strategy use. Gender was highly correlated with cognitive and compensation strategies [Sig. (2-tailed) $<0.01$ ]. The correlation was at a significant level [Sig. (2-tailed) $<0.05]$ in affective strategies. However, in memory strategies, metacognitive strategies and social strategies, the correlations were not significant.

\subsection{The differences among the students in three grades}

The study revealed that students in all three grades were medium users of learning strategies, with Grade 1 students using strategies a bit more (Total $\mathrm{M}=2.91$ ) and Grade 3 students using strategies least (Total $\mathrm{M}=2.76$ ).

Table 4 in this study indicated that the means of each category descended as grade went up with the exception of compensation and metacognitive strategies. In compensation strategy use, students in Grade 1 had the highest mean while students in Grade 2 had the lowest mean. As for metacognitive strategies, Grade 2 had the highest mean with Grade 3 the lowest.

\section{Discussion and analysis}

\subsection{The overall learning strategy use}

The means of six categories are all below 3.5, which indicate that students in senior high schools in China are medium users of language learning strategies. Students prefer using direct strategies to indirect strategies. The most frequently used learning strategies are compensation strategies $(\mathrm{M}=3.48)$, with the particular item "I read English without looking up every new word" $(M=3.82>3.5)$ at the highest. This result is similar to that of Mochizuki (1999), but different from that of Li Jiongying (2002). The reasons for students using more compensation strategies may be related to their English proficiency. According to Oxford (1990), compensation strategies belong to direct strategies, 
which involve more production of concrete details of the target language such as practice of language form and the reworking of the learning materials. Some basic features of compensation strategies are using mother tongue, asking someone for help by hesitating so that the person or teacher may provide the missing expression in the target language, using gestures or avoiding communication partially or totally when difficulties are anticipated. Less proficient learners need these compensatory strategies more because they run into knowledge roadblocks more often than learners who are more proficient in the target language. Therefore, the study's result tells us that senior high school students in China are not proficient English learners. They are still lack of vocabulary and enough language knowledge. In order to reach the aims of communication, they have to use compensation strategies.

Another result of the overall pattern is that social strategies are the least frequently used, which indicates that senior high school students in China do not favor using social strategies in learning English. This result matches Li Jiongying's (2002) findings though her participants were university students. She concludes that Chinese students' English learning is more or less confined to the classroom settings and it is reasonable they use social strategies least frequently. The low use of social strategies by senior high school students may result from the more traditional teaching method practiced in China. In Chinese learning context, students hardly have any chance to learn English in real social context, so they have no opportunity to practice the use of social strategies. However, students using social strategies least frequently may also be related to their English proficiency. As Oxford (1990) identified, social strategies are higher order strategies that show significant effects not only in use of cooperative learning, asking questions, but also in use of higher-level cognitive strategies, more language practice opportunities and greater use of different language functions. The use of social strategies can be identified as a kind of demonstration of higher proficiency by users. In this way, some social strategies tend to be used by learners who are competent enough in the target language. This could be proved by the study of Hong-Nam and Leavell (2006), which showed that the most frequently used strategies for the advanced group were social strategies. From this study, we can say that although senior high school students in China have learned English for at least more than three years, they are still not very competent in English, especially in using English in social context.

\subsection{The relationship between learning strategy use and gender}

This study shows that there is a significant correlation between learning strategy use and gender in senior high schools. High correlations are found in cognitive, compensation strategies [Sig. (2-tailed) $<0.01$ ], and a significant correlation exists between gender and affective strategies [Sig. (2-tailed) $<0.05$ ]. We can come to the conclusion from this study that females in senior high schools use cognitive strategies more frequently than males, such as previewing the lesson, remembering sentence structures, taking notes frequently and deducing the language rules. In aspect of compensation strategies, females also use more effective strategies than males. For example, females can frequently use synonyms to replace unknown words and can guess to understand unfamiliar English words or what others will say next in the conversation.

In senior high schools in China, we can find females generally do better in English than males. This phenomenon may be related to the use of English learning strategies because females use more learning strategies related to English learning than males and females are more active in using learning strategies to get effective learning. Another reason may be that females are more stable than males in attitude and learning motivation, because they are more mature in physical and psychological development. Females are willing to work hard and use learning strategies to improve their learning while males are indulgent in playing.

\subsection{The relationship between learning strategy use and grades}

As for the differences among three grades, students use learning strategies less frequently as they go into higher grades. This result is somewhat surprising and confusing. In our normal opinion, with students becoming more physically and psychologically mature, they should use learning strategies more often. However, it is not the case in this study. The reason for this may be due to the great pressure of university entrance examination that senior high school students face. In Grade One and Grade Two in senior high schools, teachers usually teach according to the materials given in the textbook. The textbook provides a lot of new knowledge and interesting passages and dialogues. In teaching, teachers always have enough time to make class more attractive to students by designing or organizing some activities. Through taking part in activities, students become more active in learning the language and have more chance to communicate with each other in English either in class or out of class. However, in Grade Three, teachers usually give students piles of exercises and tests in preparation for the university entrance examination. Students just do exercises or tests mechanically while teachers just explain the answers boringly. Under the great pressure of the coming examination, teachers are unwilling to spare time to instruct strategy use to the students and students have no chance to practice their strategy use in their daily learning. The examination-oriented teaching may explain why senior high school students in China use learning strategies less 
frequently when they reach Grade Three.

\section{Implications}

The findings of the study indicate that senior high school students in China use English language learning strategies at a medium level. This phenomenon should arouse teachers' attention in senior high schools in China because many researches have proved that strategy use is closely related to students' performance. O'Malley \& Chamot (1990) indicated that most students could benefit from the teaching of learning strategies. Therefore, teachers, especially in senior high schools, ought to increase students' awareness of strategy use and combine strategy training with their daily teaching so as to help their students improve their English performance or proficiency.

The study also reveals that senior high school students use social strategies least frequently. In fact, social strategies have a significant correlation with English performance and are an important part of learning process. Therefore, teachers should attach importance to them and create English learning atmosphere to give students more chances to take part in some social activities and cultivate their communicative ability by training them to use social strategies appropriately.

From the study, it can also be seen that female students are more able to focus their attention, take notes frequently, deduce the language rules and have clear goals for learning English, while males are not likely to concentrate on their studies and are always naughty, impatient and restless. In this case, teachers should try their best to make male students know the importance of using language learning strategies and encourage them to practice using language learning strategies appropriately so as to improve their English learning results.

Differences in using learning strategies also exist in Grade 1, 2 and 3 in senior high schools. The total means and the means of most individual strategies descend as students move to higher grades. Students in Grade 3 have less enthusiasm and interest in learning English in the boring exercising-and-checking lesson when faced with the tense entrance examination. Therefore, in order to facilitate English learning, teachers should take some measures to make the class a "happy class" to increase students' interest and relax their tired brain by instructing some strategies useful for their learning. Learning strategies can assist students in promoting their own achievement in language proficiency (Green and Oxford, 1995; O'Malley et al, 1985; Oxford, 1990).

However, teachers play a key role in increasing students' awareness of learning strategies. Teaching students the suitable language learning strategies can promote learning effectively because learning strategies are 'the special thoughts or behaviors that learners use to help them comprehend, learn, or retain new information' (O'Malley and Chamot, 1990:1) and can also foster learners' autonomy in language learning (Holec, 1981). Therefore, in strategies training, teachers themselves firstly should have enough knowledge about the language learning strategies, the students' learning needs and the learning resources available in their schools. Teachers should also provide direct instructions to cultivate students' ability to use strategies flexibly and help students summarize the use of strategies. At last, teachers should regard strategy training as an integral part of regular class routine rather than a supplementary activity.

\section{Conclusion}

This study has revealed the general pattern of language learning strategy use by senior high school students and the differences in gender and grades in Chinese context. Chinese senior high school students use compensation strategies most and social strategies least. Female students use strategies more than male students. As for the differences in grades, the higher grade the students are in, the less frequently they use learning strategies. As researches and studies in the field of language learning strategies show us, learning strategy use is closely related to the students' academic performance and teachers can assist the language learning process by promoting language learning strategy awareness and use. Therefore, teachers in senior high schools and universities should pay special attention to the use of language learning strategies among students and train them to use strategies that are beneficial for them on the basis of the differences in their characters. Only by combining strategy instruction with the teaching content appropriately can teachers achieve satisfactory teaching results.

\section{References}

Cook, V. (1991). Second Language Learning and Language Teaching. London: Edward Arnold.

Ehrman, M. \& Oxford, R. (1989). Effects of sex differences, career choice, and psychological type on adult language learning strategies. The Modern Language Journal, 73(1), 1-13.

Ehrman, M. \& Oxford, R. (1990). Adult language learning styles and strategies in an intensive training setting. The Modern Language Journal, 74(3), 311-327.

Ellis, R. (1994). The Study of Second Language Acquisition. Oxford: Oxford University Press. 
Green, J. M. \& Oxford, R.L. (1995). A closer look at learning strategies, L2 proficiency and gender. TESOL Quarterly, 29(2), 261-297.

Griffiths, C. (2003). Patterns of language learning strategy use. System, 31(3), 367-383.

Holec, H. (1981). Autonomy and Foreign Language learning. Oxford: Pergamon Press.

Hong-Nam, K. \& Leavell, A. G. (2006). Language learning strategy use of ESL students in an intensive English learning context. System, 34(3), 399-415.

Larsen-Freeman, D. (1991). Second language acquisition research: staking out the territory. TESOL Quarterly, 25(2), 315-350.

LI, Jiongying. (2002). An Empirical Study on Learning Strategies of Chinese ESL Learners. Foreign Language Education, 23(1), 42-49.

Mochizuki, A. (1999). Language learning strategies used by Japanese university students. RELC, 30(2),101-113.

O'Malley, J.M. et el. (1985). Learning strategies used by beginning and intermediate ESL students. Language Learning, 35(1), 21-46.

O'Malley, J.M. \& Chamot, A.U. (1990). Learning Strategies in Second Language Acquisition. Cambridge: Cambridge University Press.

Oxford, R.L. (1990). Language Learning Strategies: What Every Teacher Should Know. New York: Newbury House Publishers.

Oxford, R.L. \& Nyikos, M. (1989) Variables affecting choice of language learning strategies by university students. The Modern Language Journal, 73(3), 291-300.

Park, G.P. (1997). Language Learning strategies and English proficiency in Korean University. Foreign Language Annals, 30(2), 211-221.

Rigney, J.W. (1978). Learning strategies: a theoretical perspective. In: H. F. O’Neil (Jr) (Ed), Learning Strategies. New York: Academic Press. pp.165-205.

Robin, J. (1975). What the 'good language learner' can teach us. TESOL Quarterly, 9(1), 41-51.

Stern, H.H. (1975). What can we learn from the good language learner? Canadian Modern Language Review, 34, 304-318.

Stern, H.H. (1992). Issues and Options in Language Teaching. Oxford: Oxford University Press.

Table 1. Descriptive statistics for all the learning strategy categories

\begin{tabular}{lcc} 
Category & Mean & SD \\
\hline Memory & 2.69 & 0.45 \\
Cognitive & 2.79 & 0.59 \\
Compensation & 3.48 & 0.79 \\
Metacognitive & 2.91 & 0.69 \\
Affective & 2.94 & 0.78 \\
Social & 2.27 & 0.71 \\
Direct & 2.99 & 0.46 \\
Indirect & 2.71 & 0.59 \\
Total & 2.77 & 0.47 \\
\hline
\end{tabular}

Table 2 . Differences in learning strategy use between males and females

\begin{tabular}{|c|c|c|c|c|c|}
\hline \multirow{2}{*}{ Category } & \multirow[b]{2}{*}{ Mean } & Male & \multirow{2}{*}{ 76) } & \multicolumn{2}{|r|}{$(\mathrm{N}=74)$} \\
\hline & & $\mathrm{SD}$ & & $\mathrm{SD}$ & \\
\hline Memory & & 2.61 & 0.49 & 2.77 & 0.39 \\
\hline Cognitive & & 2.62 & 0.53 & 2.97 & 0.59 \\
\hline Compensation & & 3.29 & 0.89 & 3.68 & 0.64 \\
\hline Metacognitive & & 2.79 & 0.69 & 3.04 & 0.69 \\
\hline Affective & & 2.77 & 0.67 & 3.13 & 0.85 \\
\hline Social & & 2.22 & 0.73 & 2.33 & 0.69 \\
\hline Total & & 2.65 & 0.45 & 2.90 & 0.45 \\
\hline
\end{tabular}


Table 3. Correlation between gender and language learning strategies

\begin{tabular}{|l|l|l|l|l|l|l|l|l|}
\hline \multicolumn{2}{|c}{} & Mem & Cog & Com & Met & Aff & Soc & Total \\
\hline \multirow{4}{*}{ Gender } & $\mathrm{P}$ & .186 & .301 & $\begin{array}{l}.245 \\
(* *)\end{array}$ & .182 & $\begin{array}{l}.232 \\
(*)\end{array}$ & .078 & $\begin{array}{l}.270 \\
(* *)\end{array}$ \\
\cline { 2 - 9 } & $\begin{array}{l}\text { Sig.(2- } \\
\text { tailed) }\end{array}$ & .050 & .001 & .009 & .055 & .014 & .412 & .004 \\
\cline { 2 - 9 } & $\mathrm{N}$ & 150 & 150 & 150 & 150 & 150 & 150 & 150 \\
\hline
\end{tabular}

Men (Memory strategies), Cog (Cognitive strategies), Com (Compensation strategies), Met (Metacognitive strategies), Aff (Affective strategies), Soc (Social strategies).

** Correlation is significant at the 0.01 level (2-tailed).

* Correlation is significant at the 0.05 level (2-tailed).

Table 4. Descriptive statistics of learning strategies by three grades

\begin{tabular}{|c|c|c|c|c|c|c|}
\hline \multirow[t]{2}{*}{ Category } & \multicolumn{2}{|c|}{ Grade $1(\mathrm{~N}=51)$} & \multicolumn{2}{|c|}{ Grade $2(\mathrm{~N}=49)$} & \multicolumn{2}{|c|}{ Grade $3(\mathrm{~N}=50)$} \\
\hline & SD & Mean & SD & Mean & $\mathrm{SD}$ & \\
\hline Memory & 2.70 & 0.44 & 2.69 & 0.47 & 2.67 & 0.45 \\
\hline Cognitive & 2.84 & 0.56 & 2.77 & 0.58 & 2.72 & 0.64 \\
\hline Compensation & 3.58 & 0.86 & 3.31 & 0.77 & 3.48 & 0.71 \\
\hline Metacognitive & 2.91 & 0.62 & 2.93 & 0.75 & 2.88 & 0.79 \\
\hline Affective & 2.97 & 0.79 & 2.96 & 0.85 & 2.88 & 0.71 \\
\hline Social & 2.47 & 0.60 & 2.28 & 0.73 & 1.93 & 0.75 \\
\hline Total & 2.91 & 0.64 & 2.82 & 0.69 & 2.76 & 0.68 \\
\hline
\end{tabular}

